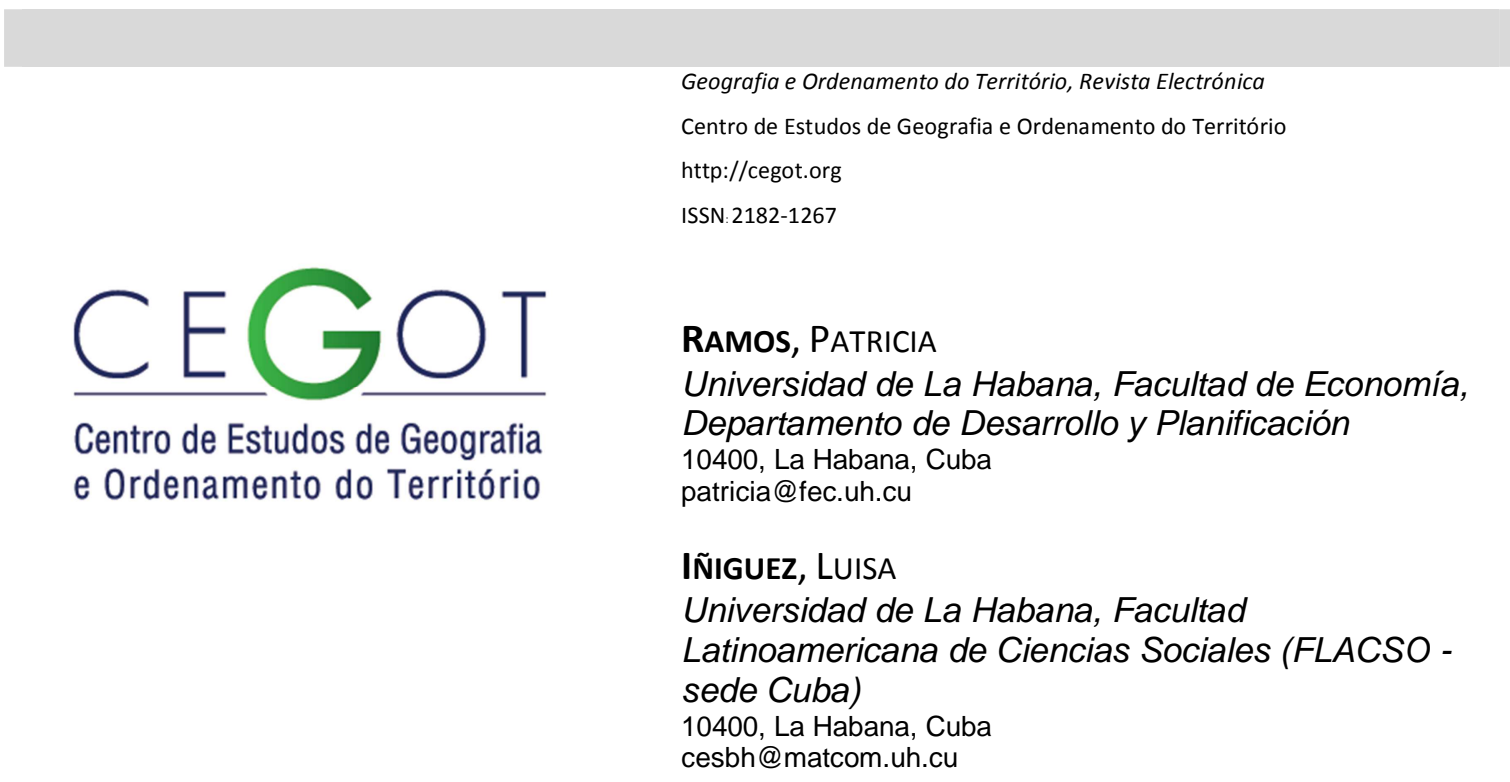

\title{
¿Nuevo rol para los territorios en Cuba? Avances y contradicciones en el contexto actual
}

\author{
A new role for the territories in Cuba? Advances and contradictions in the \\ current context \\ Um novo papel para os territórios em Cuba? Avanços e contradições no \\ contexto atual
}

Referência: Ramos, Patricia; Iñiguez, Luisa (2015). ¿Nuevo rol para los territorios en Cuba? Avances y contradicciones en el contexto actual. Revista de Geografia e Ordenamento do Território (GOT), n.ㅇ 8 (dezembro). Centro de Estudos de Geografia e Ordenamento do Território, p. 191-215, dx.doi.org/10.17127/got/2015.8.010

\section{RESUMEN}

El contexto vigente en Cuba, promueve una nueva comprensión del territorio no solo como soporte sino como agente de los cambios que se emprenden. El artículo recrea algunas de las transformaciones que han tenido lugar en la economía cubana desde una perspectiva territorial. Se muestra, de conjunto con los avances indiscutibles, la presencia de un entorno hasta cierto punto contradictorio para el desarrollo de las potencialidades de los territorios en Cuba. De un lado florece un discurso político favorable y del otro normas y regulaciones institucionales que como parte del proceso de cambios actuales apuntan a desaprovechar las oportunidades de los territorios en su ascenso económico y social.

Palabras claves: territorio, actualización, Cuba, reforma, contribución territorial, gobiernos locales. 


\section{ABSTRACT}

The current context in Cuba, promotes a new understanding of the territory not only as a support but as an agent of transformations that are undertaken. The article recreates some of the changes that have taken place in the Cuban economy from a territorial perspective. It shows, in conjunction with the undeniable progress, the presence of an environment somewhat contradictory for the development of the potential of the territories in Cuba. On the one hand flourishes a favorable political speech and in the other hand, some institutional rules and regulations as part of the current changes aim to misspend the opportunities of territories in their economic and social advancement.

Keywords: territory, updating, Cuba, reform, property tax, local governments.

\section{RESUMO}

A situação atual em Cuba promove uma nova compreensão do território, não só como um instrumento de apoio mas também como um agente das transformações que são realizadas. $\mathrm{O}$ artigo reproduz algumas das alterações ocorridas na economia cubana partir de uma perspetiva territorial, demonstrando, juntamente com o inegável progresso, a presença de um ambiente algo contraditório, relativamente ao desenvolvimento do potencial dos territórios em Cuba. Por um lado, desenvolve um discurso político favorável e por outro lado, algumas normas e regulamentos institucionais, como parte das mudanças atuais, levam a desperdiçar as oportunidades dos territórios no seu avanço económico e social.

Palavras-chave: território, atualização, Cuba, reforma, imposto sobre a propriedade, os governos locais.

El contexto actual de cambios en el funcionamiento de la economía y la sociedad en Cuba promueve una nueva comprensión del territorio como variable clave de las trasformaciones. Hasta ahora, la planificación en los niveles locales ha estado sujeta a una alta intervención del Estado central con muy pocos espacios para la autodeterminación territorial. Sin embargo, con el proceso de Actualización ${ }^{1}$ se ha hecho explícito el propósito de "impulsar con efectividad la iniciativa de los territorios para potenciar de manera sostenible su desarrollo económico"².

Algunas medidas ya instrumentadas tienen impacto directo en la escala territorial. Entre las de mayor amplitud y trascendencia puede citarse: la aprobación de ajustes a la División Político-Administrativa (DPA) de 1976, aprobados en Agosto del 2010 y puestos en vigor en

\footnotetext{
${ }^{1}$ Actualización es el término que ha adoptado el proceso de transformaciones del modelo económico y social en Cuba a partir de la celebración en el 2011 del VI Congreso del Partido Comunista de Cuba (PCC).

${ }^{2}$ Lineamientos de la Política Económica y Social del Partido y la Revolución aprobados en el VI Congreso del PCC (2011). Introducción. Pág. 8.
} 
enero del $2011^{3}$; la introducción en el 2012 de un modelo de gestión novedoso en calidad de "experimento" en las nuevas provincias Artemisa y Mayabeque ${ }^{4}$ y el establecimiento en este propio año de la Contribución Territorial para el Desarrollo Local, tributo a cuyo pago están obligadas las empresas, sociedades mercantiles de capital totalmente cubano y las cooperativas, por sus establecimientos en los municipios ${ }^{5}$.

Otras disposiciones también recientes, presentan un impacto menos claro en las dinámicas territoriales. Ejemplo de ello son la aprobación de la Ley para incentivar la Inversión Extranjera (IE); las transformaciones del sistema empresarial estatal -con la creación de las Organizaciones Superiores de Dirección Empresarial (OSDE) a las cuales la definen funciones similares a las de un holding, la reducción y concentración de empresas estatales, así como el incremento de la autonomía de las mismas -; y el estímulo al naciente sector privado (conocido en Cuba como sector por Cuenta Propia) que empieza a insertarse paulatinamente en el tejido empresarial nacional. Estas transformaciones, aunque esperadas, despiertan preocupación respecto a cuál será la reacción de los territorios ante tales procesos, dada la ausencia de una óptica territorial en algunas de estas medidas.

Este hecho, unido a la existencia de un marco institucional que impide desterrar prácticas verticalistas y centralizadoras previas, refleja que la voluntad política existente para impulsar la escala territorial no consigue acompañarse de medidas que la secunden en este propósito, al menos en la etapa que corre para la reforma. Entonces el objetivo del presente artículo es demostrar cómo a pesar de los avances, el entorno actual se erige hasta cierto punto contradictorio para el desarrollo de las potencialidades de los territorios en Cuba. De un lado emerge un discurso político potenciador y del otro la presencia de normas, regulaciones institucionales y medidas que como parte del proceso de cambios actuales

\footnotetext{
${ }^{3}$ Ver Ley No. 110/10 de la Asamblea Nacional del Poder Popular (ANPP) modificativa de la Ley No. 1304 del 3 de julio de 1976, de la División Político Administrativa, publicada en la Gaceta Oficial de la República de Cuba No. 023 Extraordinaria del 2 de septiembre de 2010. Aun cuando esta medida no potencia a priori la iniciativa de los territorios se considera útil enunciarla como primera transformación de impacto dentro de una ruta crítica orientada a su renovación.

${ }^{4}$ Ver Decreto 301 del Consejo de Ministros sobre las Funciones Estatales y de Gobierno en Artemisa y Mayabeque del 12 de octubre de 2012. En este experimento se introducen cambios institucionales relativamente significativos que buscan elevar la eficacia de las administraciones locales a partir de modificar funciones en los órganos de gobierno, reducir el tamaño de la burocracia, simplificar trámites y acercar servicios a la población, entre otros elementos.

${ }^{5}$ Ver Ley No. 113 del Sistema Tributario, publicada en la Gaceta Oficial No. 053 Ordinaria del 21 de Noviembre de 2012.
} 
apuntan a desaprovechar las oportunidades de los territorios para su ascenso en las dimensiones económicas y sociales.

El trabajo se estructura en tres partes, en la primera se expone de forma sintética un análisis de algunas de las medidas que en los últimos cinco años han impactado en los territorios de manera directa. En la segunda parte se desarrollan una serie de elementos que omiten la escala territorial o simplemente entorpecen el funcionamiento potencial de estos y que permiten arribar a las consideraciones finales en la tercera parte.

\section{Mirada a las transformaciones recientes con una perspectiva territorial}

\subsection{Cambios de funcionamiento}

Una de las medidas con que se inició la ola de transformaciones emprendidas en Cuba desde finales de la década pasada, fue la aprobación de ajustes a la DPA vigente, que incrementó las provincias a 15 con la subdivisión de la provincia de La Habana en dos Artemisa y Mayabeque - y redujo en uno - Varadero - el total de municipios del país, que ahora totalizan 168. Experimentaron ligeras variaciones en áreas y población 106 municipios, a excepción de cambios notables en unos pocos de la parte centro oriental y oriental del país 6 .

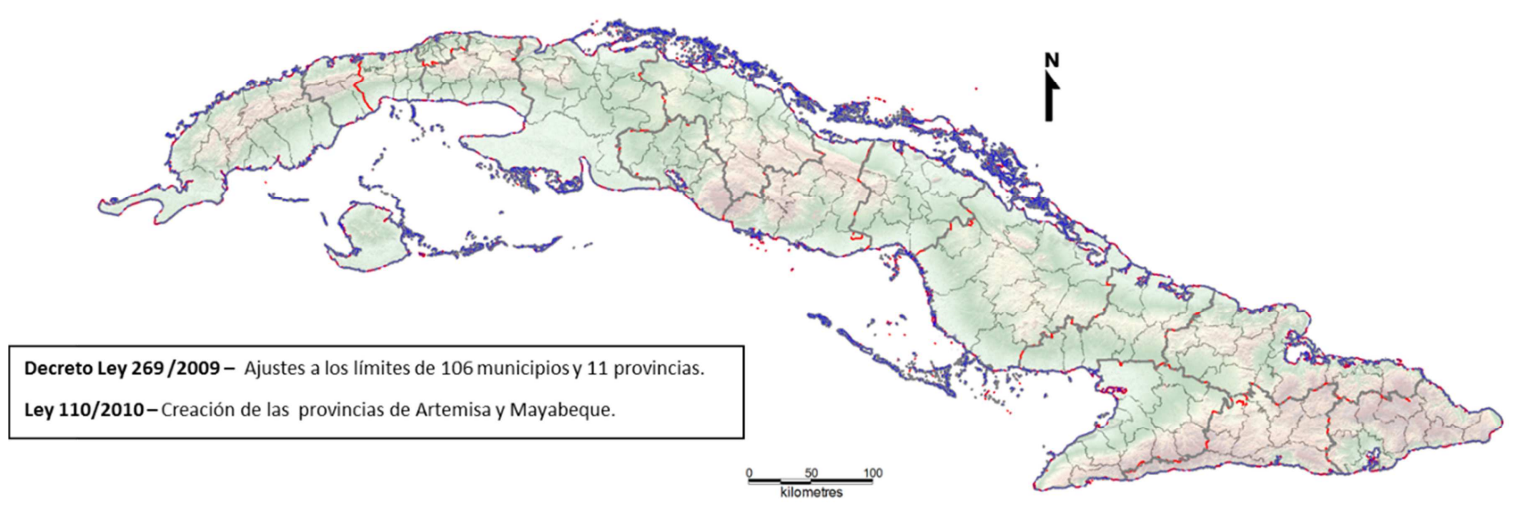

Gráfico 1 - Ajustes a la DPA en Cuba en el año 2010 Fuente: Elaborado por las autoras.

\footnotetext{
${ }^{6}$ Véase el Gráfico 1.
} 
Como propósito de los cambios se enunció la necesidad de favorecer las labores de los gobiernos y las administraciones en cada territorio, lo cual se concreta en la necesidad de corregir la distorsión para la antigua provincia La Habana de no contar con municipio cabecera y donde todas sus direcciones administrativas radicaban en la antigua provincia Ciudad de La Habana, ahora La Habana. Igualmente, al tratarse de dos provincias cuyas estructuras de gobierno se fundaban desde cero, estas constituían un terreno fértil para experimentar.

Lo cierto es que con independencia de los disímiles recortes a los que está sometido el territorio cubano, la DPA tiene un rol de peso por ser donde se asientan los aparatos locales de gobierno con la posibilidad de orientar a los actores hacia objetivos que no sean territorialmente contradictorios ${ }^{7}$.

Una marcada heterogeneidad entre los municipios en términos de área y cantidad de población, constituye hoy un punto de partida para Cuba, lo que aunque ocurre en muchos países y es un fenómeno difícilmente evitable, no puede desconocerse al momento de la toma de decisiones nacionales ${ }^{8}$. De ahí que todos los datos que condicionan las demarcaciones sub-nacionales son indispensables y se precisa desterrar prácticas de compartimentación innecesarias que entorpecen el avance en el camino al progreso por sesgos de información en el trayecto.

Desde la creación de los Órganos Locales del Poder Popular (OLPP) en 1976, los Consejos de Administración (provinciales y municipales) ${ }^{9}$ y de las Asambleas Provinciales y Municipales del Poder Popular habían estado presididos por la misma persona. Con ello, si bien se evitaban -entre estos dos entes- potenciales conflictos, interpretados como debilitadores de la noción de "unidad" que ha regido la institucionalidad cubana durante el período de la Revolución, también se anulaba el ejercicio real del gobierno por parte de la asamblea, al quedar esta última completamente anegada entre las urgencias administrativas de su

\footnotetext{
${ }^{7}$ En Î́niguez (2013) se señala la existencia de otros recortes que en ocasiones fragmentan provincias y municipios, o agregan varios de ellos en regiones para diferentes fines. Ejemplo de ello son los recortes administrativos sectoriales, institucionales, agrícolas, los que establece la propia naturaleza, o ejemplos aún más simples como el caso de la región que define el acceso a algunas carreras universitarias.

${ }^{8}$ Es posible encontrar municipios con una extensión de pocos $\mathrm{Km}$ cuadrados y otros de más de 4000 , o algunos de menos de 10000 habitantes y otros con más de 400 000, o con 2 asentamientos rurales a más de 100 (Iñiguez, 2013).

${ }^{9}$ Puede encontrarse con las abreviaturas CAP para las provincias, y CAM para los municipios.
} 
presidente dual. Posterior al establecimiento de los ajustes a la DPA, como parte del proceso de cambios en las estructuras locales, en Agosto de 2011 se aprobó experimentalmente la separación en dos entes bien delimitados de la dirección de los consejos de administración locales y las asambleas en las nuevas provincias Artemisa y Mayabeque.

Además de esta tentativa de separación de poderes, el experimento implicaba grosso modo el tránsito a un modelo de uso racional de los recursos humanos y materiales concentrando oficinas y funciones, y también, el establecimiento de un status de profesional de la política a determinados puestos en las asambleas que hasta el momento se habían acometido de forma voluntaria -en tiempo extralaboral- por ciudadanos que desempeñaban otra labor como su principal. ${ }^{10}$ Para el desarrollo de esta experiencia en toda su extensión se propuso un cronograma de trabajo que inicialmente pretendía no sobrepasar los 18 meses. ${ }^{11}$

Como todo nuevo cambio en el diseño de los mecanismos de funcionamiento, se han apreciado algunos aspectos negativos en la experiencia, con un matiz subjetivo importante. La mayor atención que por parte de los presidentes y vicepresidentes de las asambleas se esperaba para con los presidentes de los Consejos Populares ${ }^{12}$ y de Comisiones Permanentes de Trabajo, así como con los delegados en general a partir de su liberación de las funciones administrativas, no ha llegado a su máxima potencialidad enfrentando la barrera del cambio de mentalidad. Lo anterior se refleja en el quehacer permanente de la Asamblea, fundamentalmente en la figura de su presidente, que aún siente de su competencia, decisiones que son ahora de la Administración. No obstante, en el contexto anterior el presidente estaba comprometido con los resultados de la gestión de la administración local y eso limitaba su control y exigencia hacia esta. En la actualidad la

\footnotetext{
${ }^{10}$ Este es el caso de los presidentes de las Comisiones Permanentes de Trabajo de las Asambleas Provinciales, encargados del seguimiento a temas específicos por lo general altamente especializados.

${ }^{11}$ La generalización del experimento o incluso su sostenimiento en el tiempo, implicaría la revisión del Artículo 117 de la Constitución de la República de Cuba, que establece que "...los Presidentes de las Asambleas Provinciales y Municipales del Poder Popular son a la vez presidentes de los respectivos Órganos de Administración". (Rodríguez; Barrios \& Rodríguez Gavilán, 2011)

${ }^{12}$ Los Consejos Populares fueron creados en el año 1991, en el contexto inicial de la crisis de la década del noventa, con el propósito de acercar las estructuras de gobierno a las localidades. Para mayor información véase la Ley No. 91 de los Consejos Populares (Aprobado por la Asamblea Nacional el 13 de julio del 2000) en Documentos Normativos de la labor de los órganos del poder popular y las entidades de su subordinación. Asamblea Provincial del Poder Popular de Ciudad de La Habana. La Habana, 485 Aniversario.
} 
administración se ve obligada a rendir cuentas de su gestión ante la Asamblea sin comprometimiento entre ambas partes. ${ }^{13}$

En las administraciones municipales de los territorios que están viviendo las transformaciones, se considera que el camino por recorrer en la actividad administrativa por parte de muchos de los jefes y vicejefes de esas instancias, es todavía largo y demanda un gran esfuerzo en términos de capacitación. A su vez, hay otras carencias que no escapan a toda la economía nacional, como es el hecho de que las administraciones municipales enfrentan la dispersión en la localización física de sus instalaciones ante las necesidades de medios de transporte, de medios de automatización y de conectividad de estos últimos. ${ }^{14}$

Así, la riqueza de buenas y malas prácticas recogidas en los dos años posteriores al inicio del experimento concluyó con la decisión de extenderlo dos años más, hasta diciembre del 2016 como una propuesta del Consejo de Ministros que se enunció en Julio de 2014. El acicate fundamental para esta determinación fue la necesidad de disponer de más tiempo para obtener un mayor conocimiento en el perfeccionamiento del funcionamiento, la estructura y composición de los OLPP y de sus Consejos de la Administración, especialmente en los municipios, donde el contenido de trabajo es más complejo. ${ }^{15}$

\subsection{Nuevo tributo territorial}

Otra medida, que también tuvo como plataforma para su aplicación inicial a las provincias Artemisa y Mayabeque, fue la implementación de la Contribución Territorial para el Desarrollo Local dentro de la Ley No. 113 “Del Sistema Tributario" aprobada en Noviembre de 2012. En esta norma se establece un tributo a cuyo pago "están obligadas las empresas, sociedades mercantiles de capital totalmente cubano y las cooperativas, por sus

\footnotetext{
${ }^{13}$ Información obtenida a partir de entrevista concedida por Raúl Rodríguez y Juan Domínguez, Jefe del Consejo de la Administración y Asamblea de la provincia Artemisa respectivamente a Adianez Fernández Izquierdo, periodista de Juventud publicada por http://www.cubainformacion.tv/index.php/politica/56967-logros-en-el-nuevo-modelo-experimental-degobierno-de-la-provincia-de-artemisa el 12 de junio de 2014.

${ }^{14}$ Ídem.

${ }^{15}$ Publicado en http://www.granma.cu/cuba/2014-07-06/extienden-la-experiencia-en-artemisa-y-mayabequehasta-el-2016 el 6 de julio de 2014.
} 
establecimientos sin perjuicio del municipio en que estén enclavados" ${ }^{16}$. Hasta el momento, la poca o prácticamente inexistente participación de los municipios en la recaudación tributaria había constituido un elemento negativo señalado reiteradamente por estudiosos de este tema, dada la imposibilidad de los territorios de contar con ingresos provenientes del derrame de actividades que se desarrollaban en sus demarcaciones y que podían facilitar su reacción ante problemas de corto plazo. ${ }^{17}$

Como base imponible para esta Contribución Territorial se estableció la totalidad de los ingresos provenientes de la venta de bienes y la prestación de servicios atribuibles a cada establecimiento o a la propia empresa, sociedad o cooperativa cuando esta genere ingresos por sí misma en los municipios donde operan sus establecimientos. Por otra parte, el tipo impositivo sería el dispuesto en la Ley Anual del Presupuesto, que para los años 2014 y 2015 ha sido de un $1 \%^{18}$. En el año 2014 se decidió incorporar en la aplicación de esta Contribución Territorial además de las provincias Mayabeque y Artemisa una selección de 24 municipios vinculados al Plan de Desarrollo Integral (PDI) distribuidos por todas las provincias del país excepto La Habana. Para el año 2015, el pago de la contribución está generalizado a todos los municipios del país ${ }^{19}$.

Lo cierto es que la gradualidad en la aplicación de esta medida ha retrasado el impacto positivo esperado de la recaudación para la totalidad de los municipios del país. Por otra parte, aunque la Ley No. 113 presenta un alcance flexible en el uso de los ingresos esperados cuando se enuncia en su Artículo 314 que "los ingresos recaudados por este concepto, se destinan al financiamiento de actividades dirigidas a garantizar el desarrollo territorial sostenible, a través de la gestión de los Consejos de la Administración Municipales", su uso en la práctica se ha visto restringido por el artículo cuarto de la

\footnotetext{
${ }^{16}$ Ley No. 113 “Del Sistema Tributario, publicada en la Gaceta Oficial No.053 Ordinaria del 21 de Noviembre de 2012.

${ }^{17}$ Hay cuatro documentos de consulta obligatoria para entender las particularidades de esta medida en el momento actual: Ley No. 113, "Del Sistema Tributario" publicada en Gaceta Oficial No. 053 Ordinaria de 21 de noviembre de 2012, Ley No. 117 del Presupuesto del Estado para el año 2014, publicada en Gaceta Oficial No. 5 Extraordinaria de 20 de enero de 2014, Ley No. 119 del Presupuesto del Estado para el año 2015, publicada en la Gaceta Oficial No. 1 Extraordinaria de 9 de enero de 2015 y la Resolución 170 del Ministerio de Finanzas y Precios, publicada el 31 de marzo de 2014.

${ }^{18}$ Véanse los Artículos 81 y 97 de la Ley No. 117 del Presupuesto del Estado para el año 2014 y de la Ley No. 119 del Presupuesto del Estado para el año 2015 respectivamente.

${ }^{19}$ Artículo 95.1 de Ley No. 119 del Presupuesto del Estado para el año 2015.
} 
Resolución 170 de 2014 que establece que "los ingresos que obtengan los Consejos de la Administración de las asambleas municipales por concepto de la Contribución Territorial para el Desarrollo Local, se destinan al financiamiento de actividades previstas en el Plan de la Economía, dirigidas a garantizar el desarrollo territorial sostenible (...)". Lo anterior se ha manifestado en ingresos paralizados sin posibilidad de ser usados por no estar contemplados en el Plan, teniendo que esperar su ejecución al año siguiente con una agenda de problemas por resolver que aguarda. ${ }^{20}$

Por último, la exoneración del pago de la Contribución Territorial a los establecimientos de las empresas mixtas, de capital totalmente extranjero y los contratos de asociación económica internacional (c), establecida en el 2014 dejó afuera una parte importante de lo que podrían haber constituido ingresos frescos a los municipios del país ${ }^{21}$. También se exoneró del pago en este período a establecimientos de las empresas nacionales que previa aprobación en el Plan de la Economía inicien o ejecuten en el año 2014 procesos de inversiones constructivas de reparación o mantenimiento capital (a) y a las cooperativas de producción agropecuarias y las unidades básicas de producción cooperativa (b). En el caso de los incisos (a) y (b) la exoneración se entiende como un mecanismo indirecto de regulación que fomenta el desarrollo de cooperativas para la producción alimentaria e incentiva la reconstrucción y modernización del envejecido parque industrial cubano.

En el año 2015, se corrige en alguna medida esta tendencia cuando se establece que están sujetos al pago de este tributo durante el año 2015 las empresas mixtas, los inversionistas nacionales y extranjeros partes en contratos de asociación económica internacional y las empresas de capital totalmente extranjero, con las exenciones y exclusiones que se disponen en la Ley No. 118 "De la Inversión Extranjera”. ${ }^{22}$

\footnotetext{
${ }^{20}$ Los mecanismos del plan de la economía son rígidos en demasía, pues obligan a prever detalladamente la mayoría de las actividades o necesidades del año siguiente. Una vez aprobado este, lo que no quede contenido, habitualmente resulta muy difícil modificarlo.

${ }^{21}$ Artículo 82 de la Ley No. 117 del Presupuesto del Estado para el año 2014.

${ }^{22}$ Artículo 95.3 de la Ley No. 119 del Presupuesto del Estado para el año 2015.
} 


\section{2. ¿Por qué hablar de un enmarcamiento restrictivo para los territorios?}

Han habido otras disposiciones en las que la óptica territorial no ha estado presente con la misma fuerza. Esto, unido a la prevalencia de un marco institucional con prácticas verticalistas y centralizadoras, reduce las posibilidades de desarrollo de los territorios, que a pesar de la voluntad política de impulsarlos operan todavía en un marco que los restringe.

\subsection{Nueva Ley de Inversión Extranjera}

Algunas interrogantes surgen de la lectura de la nueva Ley de Inversión Extranjera ${ }^{23}$. En la misma se establecen como los tres niveles de decisión para la aprobación de asociaciones o negocios, al Consejo de Estado, Consejo de Ministros y Jefes de los Organismos de la Administración Central del Estad ${ }^{\circ}$ de la cartera correspondiente ${ }^{24}$. Sin embargo, ¿por qué no contemplar la participación de los CAM - o al menos de los CAP - en los niveles de aprobación considerados cuando estos serán los principales receptores físicos de los proyectos que surjan y probablemente los mayores proveedores de la fuerza de trabajo a emplear?

No es el propósito de este señalamiento burocratizar el proceso de aprobación de nuevos proyectos con la inclusión de un nuevo nivel. Sencillamente, en el ánimo de horizontalizar y confinar prácticas vetustas, se considera que el territorio como soporte tendría que tener voto. Refiriéndose a esta problemática Triana (2014) señala que con ello, la posibilidad de que los gobiernos locales compensen los déficits que tienen en materia de inversión se supedita a la decisión de otras instituciones, lo que no contribuye al entendimiento de la ley desde los niveles locales como forma de promoción de sus potencialidades.

Al propio tiempo, el régimen especial de tributación que se propone establece la exención del pago de la contribución territorial para el desarrollo local, durante el período de recuperación de la inversión a las empresas mixtas, así como a los inversionistas nacionales

\footnotetext{
${ }^{23}$ Ley No. 118 de la Inversión Extranjera aprobada por la Asamblea Nacional del Poder Popular el 29 de marzo de 2014.

${ }^{24}$ Artículo 21.1 de la Ley No. 118 de la Inversión Extranjera.
} 
y extranjeros partes en contratos de asociación económica. ${ }^{25}$ La interrogante sería ¿por qué distender tanto en el tiempo el disfrute de los beneficios fiscales para los territorios?, ¿por qué hacer prevalecer un enfoque sectorial a lo largo de toda la Ley que bien podría sumarse y contribuir, de ser otra la óptica, a los esfuerzos por lograr un desarrollo balanceado de los heterogéneos territorios de Cuba?

Lo anterior, si bien constituye un incentivo para los inversionistas, es en alguna medida un desincentivo para los territorios que tendrán que esperar períodos de tiempo acotados a un supuesto éxito de los proyectos para disfrutar los beneficios fiscales de decisiones aprobadas por instancias superiores en las que no participaron. No obstante, incrementar el estímulo a la inversión extranjera en el momento que corre para el país es una urgencia que se comparte por las autoras. Se considera que la percepción local de una inversión en la comunidad, aún cuando en términos de recaudación tributaria no signifique nada, será definitivamente positiva.

\subsection{Reorganización del sistema empresarial estatal}

Otro tema lo constituye la reorganización de los principales tipos de entidades que está teniendo lugar, con el consecuente impacto territorial. La reducción considerable de las Sociedades Anónimas, Empresas, Cooperativas y Unidades Presupuestadas, es un hecho que puede apreciarse en el Gráfico 2. Llama la atención particularmente el caso de las Empresas que en seis años han experimentado una reducción de poco más de un $30 \%$ (las Sociedades Anónimas, Cooperativas y Unidades Presupuestadas se han reducido en un $20 \%, 14 \%$ y $13 \%$ en similar período). La fusión o liquidación de algunas empresas y el tránsito de muchas a Unidades Empresariales de Base (UEB), con la pérdida de facultades que significa esto último $^{26}$, deja ver configuraciones nuevas para algunos territorios, que pierden parte de su sistema empresarial y como corolario los impactos positivos derivados de contar con estos establecimientos en sus demarcaciones.

\footnotetext{
${ }^{25}$ Artículo 42 de la Ley No. 118 de la Inversión Extranjera.

${ }^{26}$ Las UEB son consideradas por lo general establecimientos de las empresas, por lo que disponen de menores facultades para realizar su gestión.
} 
Las OSDE, han surgido como instituciones encargadas de "evaluar la creación, extinción o fusión de empresas de su Organismo o Consejo de la Administración Provincial”27. Lo anterior se ha traducido en la concentración de sistemas empresariales por ramas en correspondencia a intereses estatales, semejanzas tecnológicas y productivas con el propósito de contribuir a la separación de funciones estales y empresariales coexistentes anteriormente en los Ministerios. La preocupación acá es que impulsados por la búsqueda de la eficiencia del sistema empresarial, puedan desconocerse las implicaciones de estas decisiones para el tejido empresarial de municipios y provincias.

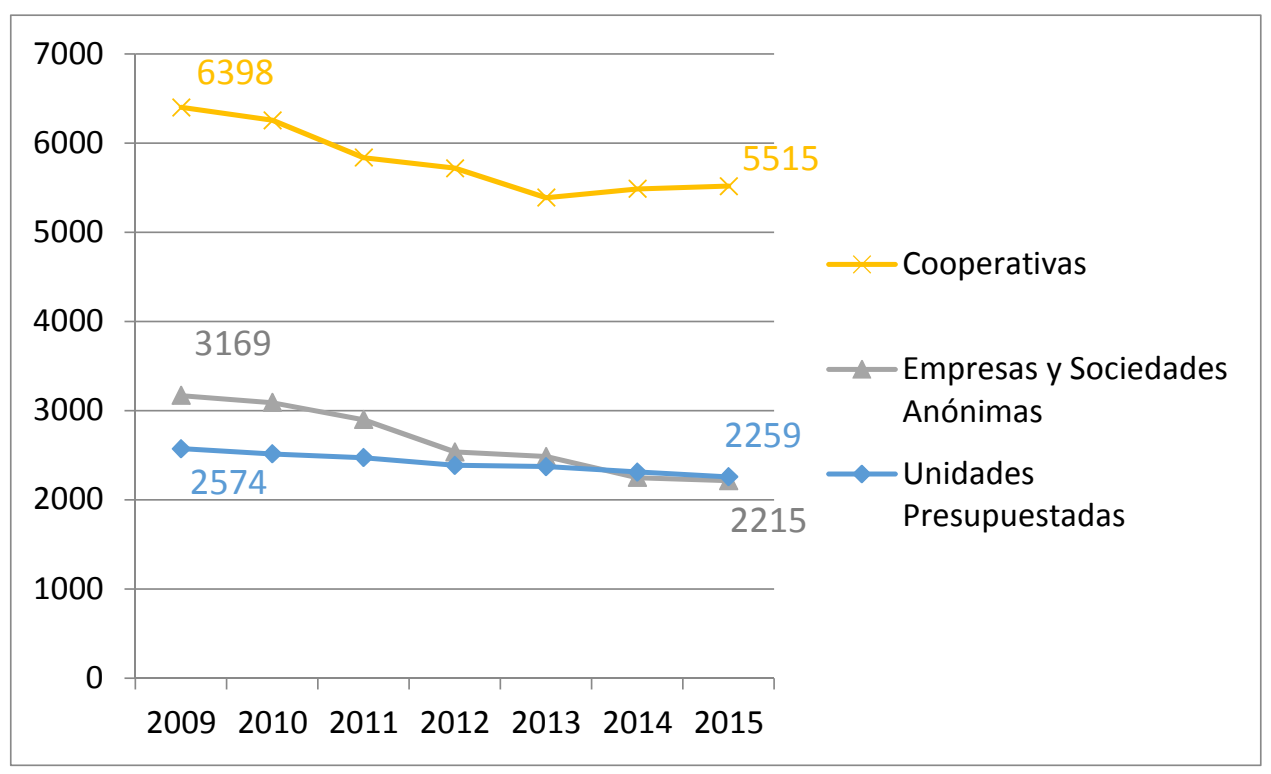

Gráfico 2 - Organización Institucional por entidades en Cuba 2009-2015

Fuente: Elaborado por las autoras a partir de datos de los Informes de Organización Institucional: Principales Entidades (2009-2015), publicación trimestral de la Oficina Nacional de Estadísticas e Información ONEI (www.onei.cu).

Un análisis por provincias refleja que la reducción del número de empresas ha sido relativamente homogénea aunque en algunas puede ser más marcada como es el caso de La Habana, Matanzas, Camagüey y Santiago de Cuba. El punto de inflexión puede apreciarse en el Gráfico 3 a partir del año 2011 en la mayoría de los $\operatorname{casos}^{28}$.

\footnotetext{
${ }^{27}$ Los cambios en el sistema empresarial cubano pueden encontrase en los siguientes documentos: DecretoLey No. 320 del Consejo de Estado, Decreto No. 323 del Consejo de Ministros, Resoluciones No. 181/2014 y 203/2014 del Ministerio de Finanzas y Precios y Resolución No. 17/2014 del Ministerio de Trabajo y Seguridad Social.

${ }^{28}$ Sobre la reducción del número de empresas Triana (2014) señala que este proceso de concentración al interior del sistema empresarial puede estar motivado por la intención de incrementar la eficiencia y la productividad a nivel nacional buscando hacer "economías de escala".
} 


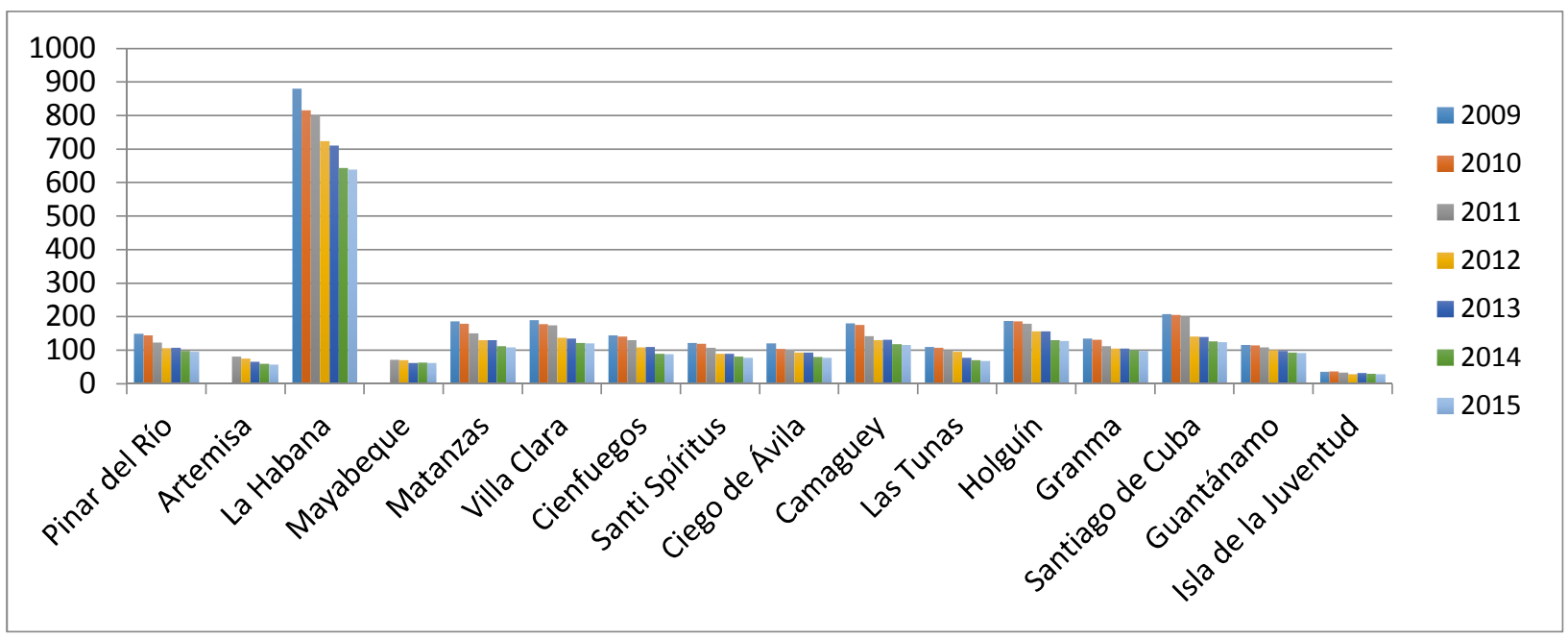

Gráfico 3 - Cantidad de Empresas por Provincia 2009-2015

Fuente: Elaborado por las autoras a partir de datos de la ONEI (www.onei.cu).

Nótese que en el caso de las Unidades Presupuestadas, como se muestra en el Gráfico 4, el comportamiento en general es estable excepto para las provincias más occidentales donde puede notarse un decrecimiento mayor.

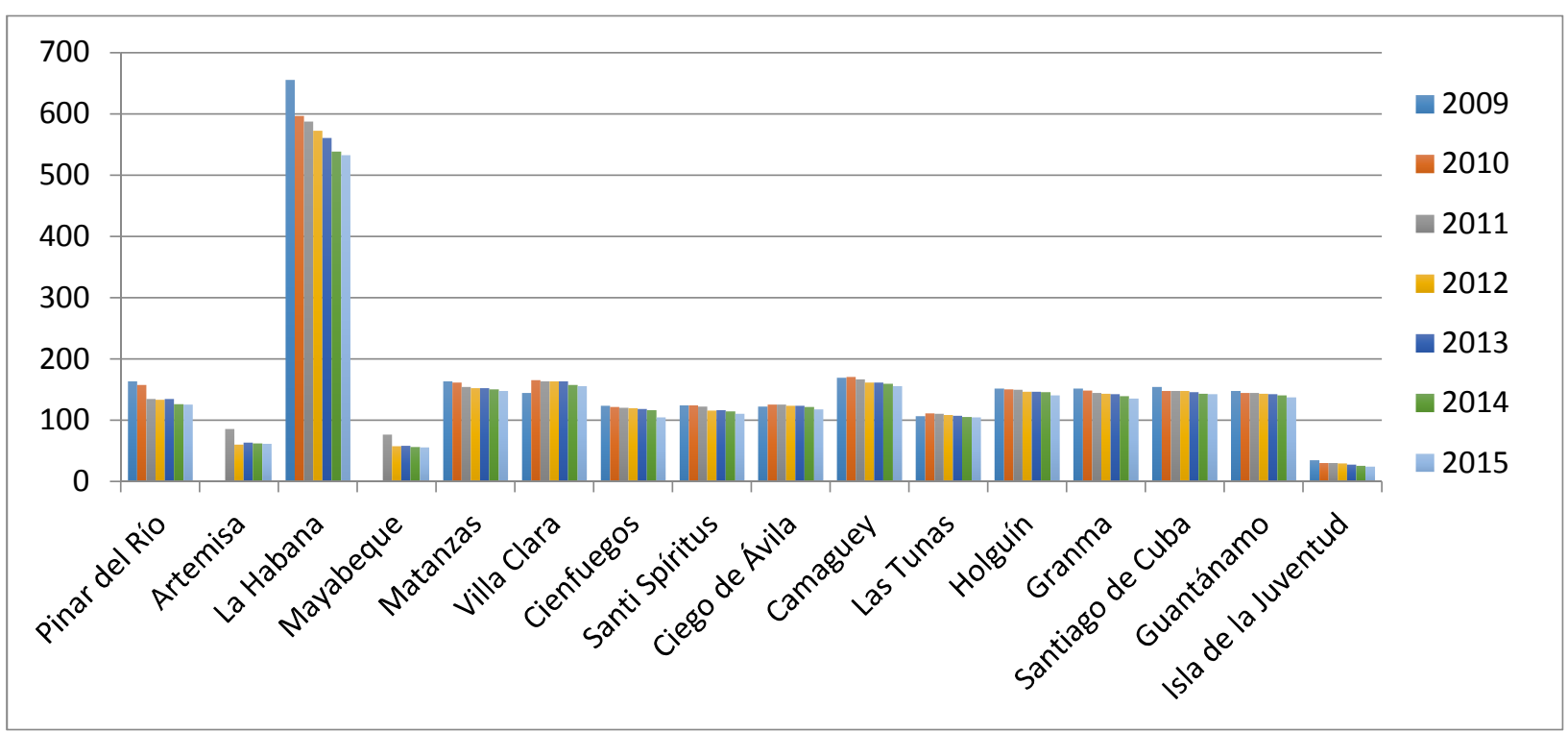

Gráfico 4 - Cantidad de las Unidades Presupuestadas por Provincia 2009-2014 Fuente: Elaborado por las autoras a partir de datos de la ONEI (www.onei.cu).

Por otra parte, la concentración de entidades por provincias refleja también disparidades que permiten interesantes lecturas. Si se considera que en cierta medida de ello dependerán los ingresos que queden para estas del pago de la contribución territorial, se 
vería como las diferencias de partida pudieran de alguna manera perpetuar la condición desventajosa que ya cargan algunas provincias y municipios. En el Gráfico 5, por ejemplo, puede apreciarse siguiendo a La Habana, a las provincias Holguín, Santiago de Cuba, Villa Clara y Pinar del Río, como aquellas que por la cantidad de entidades que concentran en sus demarcaciones mayores beneficios pudieran percibir. ${ }^{29}$

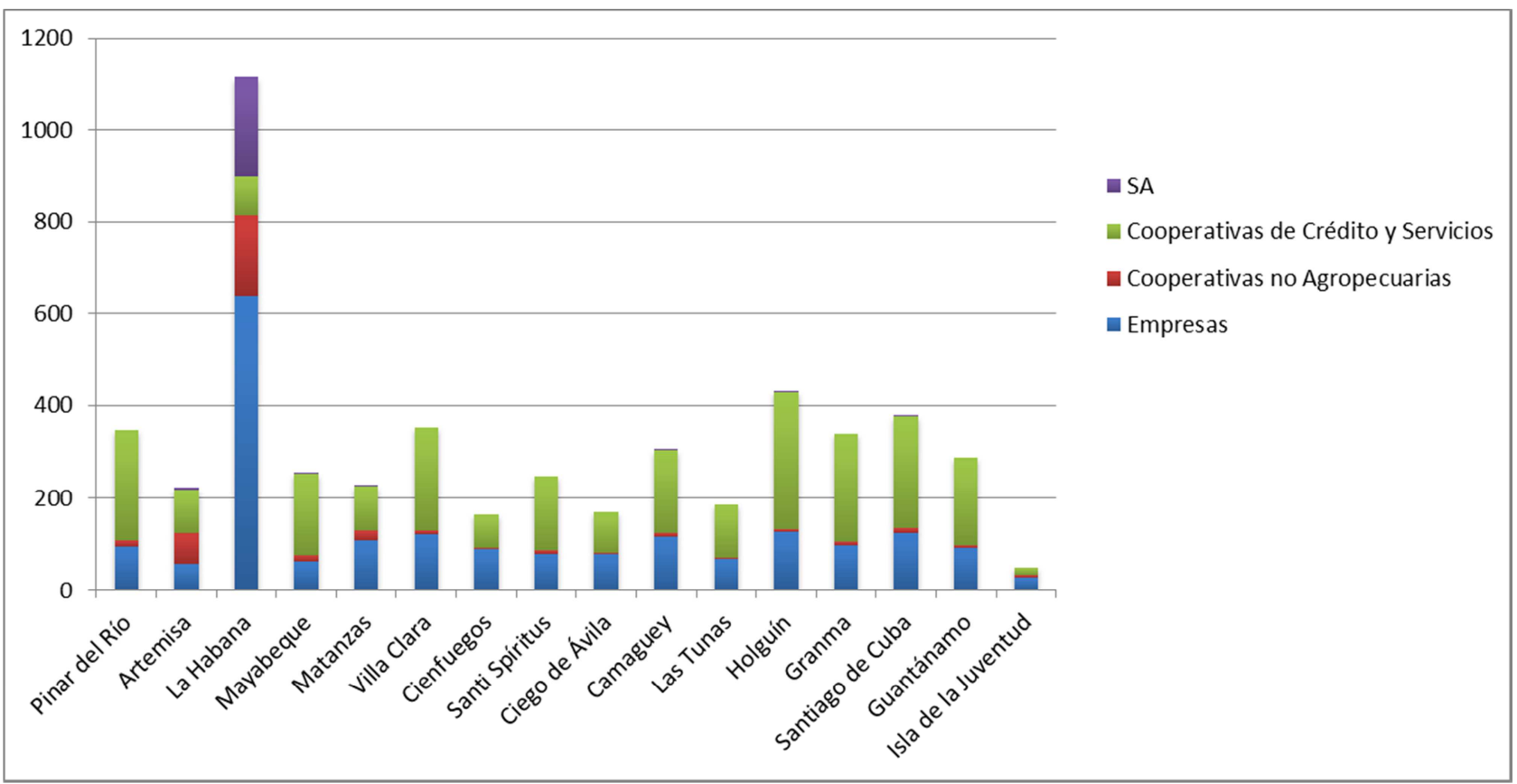

Gráfico 5 - Entidades económicas sujetas al pago de la Contribución Territorial por Provincias en Marzo de 2015

Fuente: Elaborado por las autoras a partir de datos de la ONEI (www.onei.cu).

Hay otros matices que pudieran añadirse a este análisis. Hay un efecto para los territorios en función del tipo de entidad que acoge no solamente en términos de ingresos, sino también en términos de autonomía para influir en su gestión y en la toma de decisiones. Una regularidad es que la gran mayoría de las entidades radicadas en los municipios son de subordinación nacional o provincial, quedando unas pocas entidades en su mayoría de servicios para la subordinación municipal. El esquema institucional establecido en 1975 según el cual la actividad económica del territorio se encontraba dividida en dos grandes

\footnotetext{
${ }^{29}$ En cualquier caso aunque esta es una variable a seguir, no debe tomarse como regularidad estricta, pues la base que se impone con la Contribución Territorial es la totalidad de los ingresos provenientes de la venta de bienes y la prestación de servicios atribuibles a cada establecimiento o a la propia empresa, con lo cual no será la cantidad de establecimientos sino los ingresos generados por estos lo que defina los beneficios para los territorios correspondientes.
} 
grupos de entidades, las de subordinación local que incluían los niveles provincial y municipal y las de subordinación nacional, se ha mantenido prácticamente invariable y ha ponderado la visión sectorial por encima de la territorial ${ }^{30}$. Nuevos actores han aparecido y permanecen fuera del radio de acción de este diseño, es el caso del llamado sector de los trabajadores por cuenta propia.

El creciente sector privado en Cuba - o de trabajadores por cuenta propia -tiene que ser necesariamente asumido por las autoridades territoriales como un componente clave del sistema productivo empresarial de los territorios. Su estímulo, como política estatal desde el año 2010, ha sido definitivamente una de las medidas que ha cambiado las configuraciones del territorio. Asumirlos e integrarlos en las dinámicas territoriales resulta imprescindible en el propósito de buscar soluciones desde adentro a problemas de menor envergadura. Este sector compone el entorno local y las autoridades locales pueden y deben aprovecharse de eso buscando la interacción y complementariedad entre este y la esfera pública.

La omisión de los trabajadores por cuenta propia en las Indicaciones Metodológicas para la elaboración del Plan de la Economía - anualmente emitidas por el Ministerio de Economía y Planificación (MEP) -, en su acápite para la Planificación Territorial correspondiente a los años 2014 y recientemente para el 2015, son una muestra de que este tópico es aún un obstáculo por superar. En este sentido una importante transformación, tal vez la más generalizada es el cambio de gestión de la actividad agropecuaria con el actual predominio de formas cooperativas consideradas no estatales, las que son numéricamente superiores.

\subsection{Incongruencias institucionales}

Algunos de los señalamientos anteriores son el resultado de la existencia de una concepción tradicional de la planificación en la que solo se incluye aquello en lo que es posible influir de manera directa. La siguiente noción de planificación territorial contenida en las Indicaciones Metodológicas para la elaboración del Plan 2015 es muestra de ello: "abarca dos esferas con tareas y objetivos de desarrollo económico y social propios: la elaboración de los planes de

\footnotetext{
${ }^{30}$ Las actividades de subordinación local se encuentran bajo la conducción de los órganos del poder popular, y las de subordinación nacional son lideradas desde los correspondientes Organismos de la Administración Central del Estado (OACE).
} 
las actividades de subordinación local y el plan territorial en su conjunto, que integra las actividades locales y nacionales desarrolladas en un espacio común (municipio, provincia, zona, área), los que deben integrarse a los planes ramales y la economía nacional en su conjunto". 31

Hoy los canales por los que corre la planificación territorial son como mínimo engorrosos y requieren ser actualizados considerando, entre otros factores, el propio incremento de la actividad privada difícil de conducir por los acostumbrados mecanismos directos de regulación. Solo las mencionadas entidades de subordinación local y nacional se insertan en el actual sistema de planificación territorial al tiempo que están sujetas a múltiples niveles de subordinación y mecanismos de asignación que tejen un entramado difuso para desplegar las potencialidades de los territorios ${ }^{32}$.

El ejercicio del poder se vierte en estas entidades por diversas vías. Los Organismos de la Administración Central del Estado (OACE) ejercen sobre ellas una atención metodológica, la cual comprende los aspectos que norman la actividad ramal de que se trate. En el caso de las entidades de subordinación nacional se ejerce la dirección empresarial también desde Ios OACE por lo que no es complejo hacer coincidir en estas entidades el enfoque ramal con el institucional ${ }^{33}$. Sin embargo, la dirección empresarial hacia las entidades de subordinación local la emprenden los CAP o CAM en función a si la subordinación es provincial o municipal respectivamente, por lo que acá se hace coincidir el enfoque institucional y el territorial ${ }^{34}$. Por otra parte el financiamiento para inversiones y las asignaciones materiales de recursos se realizan desde el Ministerio de Economía y Planificación (MEP) a los OACE y Consejos de la Administración que a su vez distribuyen a sus respectivas entidades de subordinación. A

\footnotetext{
${ }^{31}$ Indicaciones Metodológicas para la elaboración del Plan 2015.

${ }^{32}$ Sobre el problema de la "subordinación", puede encontrarse en íñiguez (2014) un punto interesante: "En el camino hacia nuevas formas de concebir la pertenencia y la gestión de los territorios económicos a niveles supra municipales, podría de inicio eliminarse el incómodo término "subordinación", por otro que contemple la necesaria innovación en las relaciones entre niveles, y el equilibrio entre los poderes en el territorio. Estas innovaciones políticas, permitirán sustituir la representación de escollos para el gobierno municipal, por oportunidades y beneficios a la vida territorial".

${ }^{33}$ Los intereses territoriales en este caso no influyen de forma directa. En la práctica, aunque existen instrumentos o espacios que persiguen la conciliación de los planes con las autoridades locales, la existencia de un diseño institucional carente de mecanismos que potencien los derrames, conduce a que un buen desempeño de la entidad de subordinación nacional no necesariamente tribute a los objetivos de desarrollo interno del territorio, e incluso puede presentar antagonismos.

${ }^{34}$ Las potenciales contradicciones podrían encontrarse aquí entre los territorios y lo que dictamine el OACE rector de la rama en su ejercicio de rector metodológico.
} 
esta armazón se integra una función estatal reguladora que descansa en los Consejos de la Administración, a partir de su responsabilidad estatal con lo que acontece en sus demarcaciones, y que incluye desde el cuidado del medio ambiente hasta el uso racional de los recursos de su competencia.

Esta última, es una función que normalmente se ejerce desde los Consejos Populares. Aunque supuestamente estos ofrecen una excelente institucionalidad en el propósito de velar por los intereses del territorio integralmente, una revisión de su legislación muestra incoherencias que reducen lo potencialmente ventajoso de este diseño institucional. Cuando por ejemplo, se plantea que “(...) los Consejos Populares (...) representan a la demarcación donde actúan y a la vez son representantes de los órganos del Poder Popular municipal, provincial y nacional" se deja margen a la ocurrencia de conflictos al no definirse con claridad a qué figura representan ante una controversia, si a los órganos superiores del Estado, la provincia, el municipio o la población de la demarcación donde actúa.

Asimismo, definir entre sus facultades, la de exigir por el cumplimiento de las políticas trazadas por los órganos superiores del Estado por un lado, y la de trabajar activamente para que se satisfagan las necesidades de la población de su demarcación por otro, son objetivos que pueden presentar franjas de potenciales contradicciones.

La ley de los Consejos Populares también establece que “(...) su principal función es velar por el desempeño de las entidades radicadas en el territorio", con independencia de su nivel de subordinación. Esto los inviste de atribuciones difícilmente alcanzables. Un presidente de Consejo Popular está amparado legalmente según esta disposición para exigir a una entidad de subordinación nacional - como puede ser la empresa del níquel en el municipio Moa -, por el cumplimiento de su plan de producción, lo que a juicio de las autoras constituye una distorsión. Otro tema distinto sería que el Consejo Popular se concentrara en identificar cuándo la actuación de una institución determinada provoca afectaciones en algún sentido para su población y velara por sus intereses exigiendo a estas entidades la no ocurrencia de estos eventos. En la práctica, estos se han reducido a una estructura organizativa de la cual los municipios se valen para hacer cumplir algunas de las funciones que les están confiadas. El complejo entramado de relaciones expuesto hasta aquí entorpece lejos de favorecer la actividad local. 


\subsection{Ejecución de presupuestos desde gobiernos locales}

En otro orden, un análisis cuantitativo de la participación de los gobiernos locales con respecto al gobierno central en los gastos del presupuesto del estado en los últimos años, de manera global y también en algunas partidas seleccionadas, es otro de los pilares en los que se sustenta la hipótesis de partida. El Gráfico 6 por ejemplo, ilustra una tendencia entre los años 2007 y 2013 al incremento de los gastos del presupuesto del estado ejecutados desde el gobierno central, al tiempo que se aprecia la disminución de estos en el caso de los gobiernos locales.

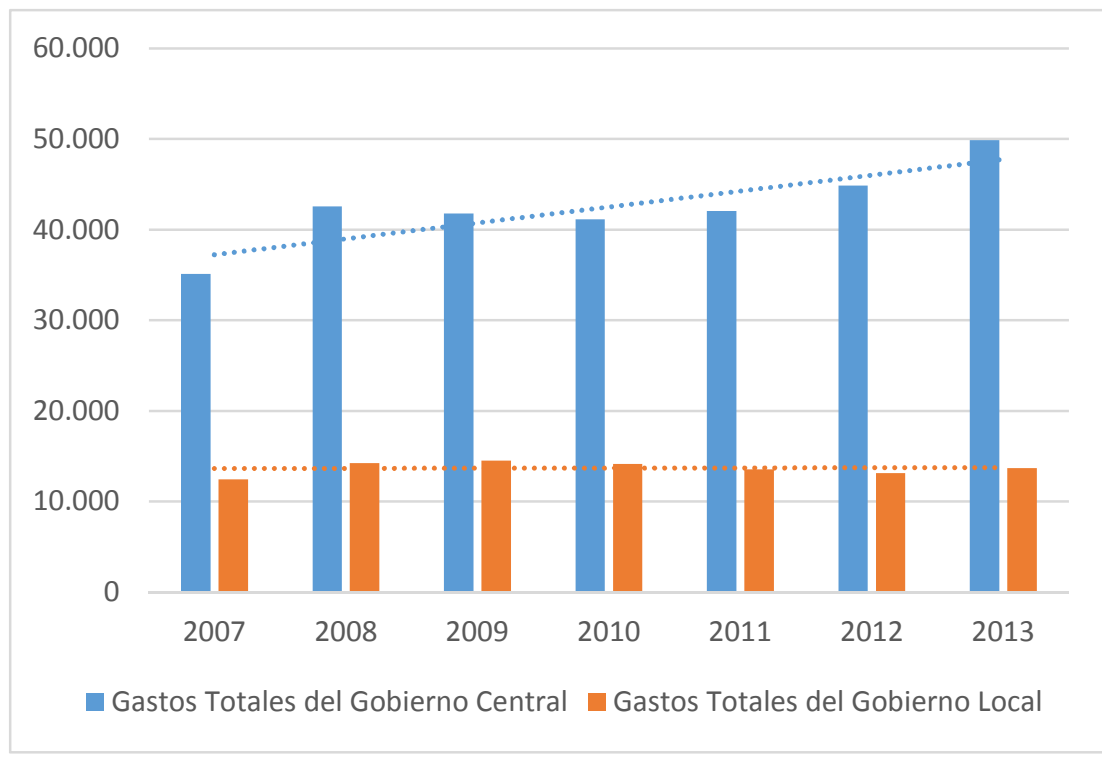

Gráfico 6 - Ejecución de los Gastos Totales del Presupuesto del Estado 2007-2013 Fuente: Elaborado por las autoras a partir de datos de los Anuarios de la Oficina Nacional de Estadísticas e Información ONEI (www.onei.cu).

En términos porcentuales, un análisis de cómo se han distribuido los gastos del presupuesto del estado entre los gobiernos locales y el gobierno central, refleja que la tendencia de los últimos años ha sido al incremento de la proporción de gastos que se ejecutan desde el gobierno central. Los números en el Gráfico 7 muestran, para los últimos siete años de los que hay información disponible, una reducción de la participación de los territorios en las decisiones de gasto del presupuesto del estado, lo cual es contradictorio con los derroteros que corren para estos. 


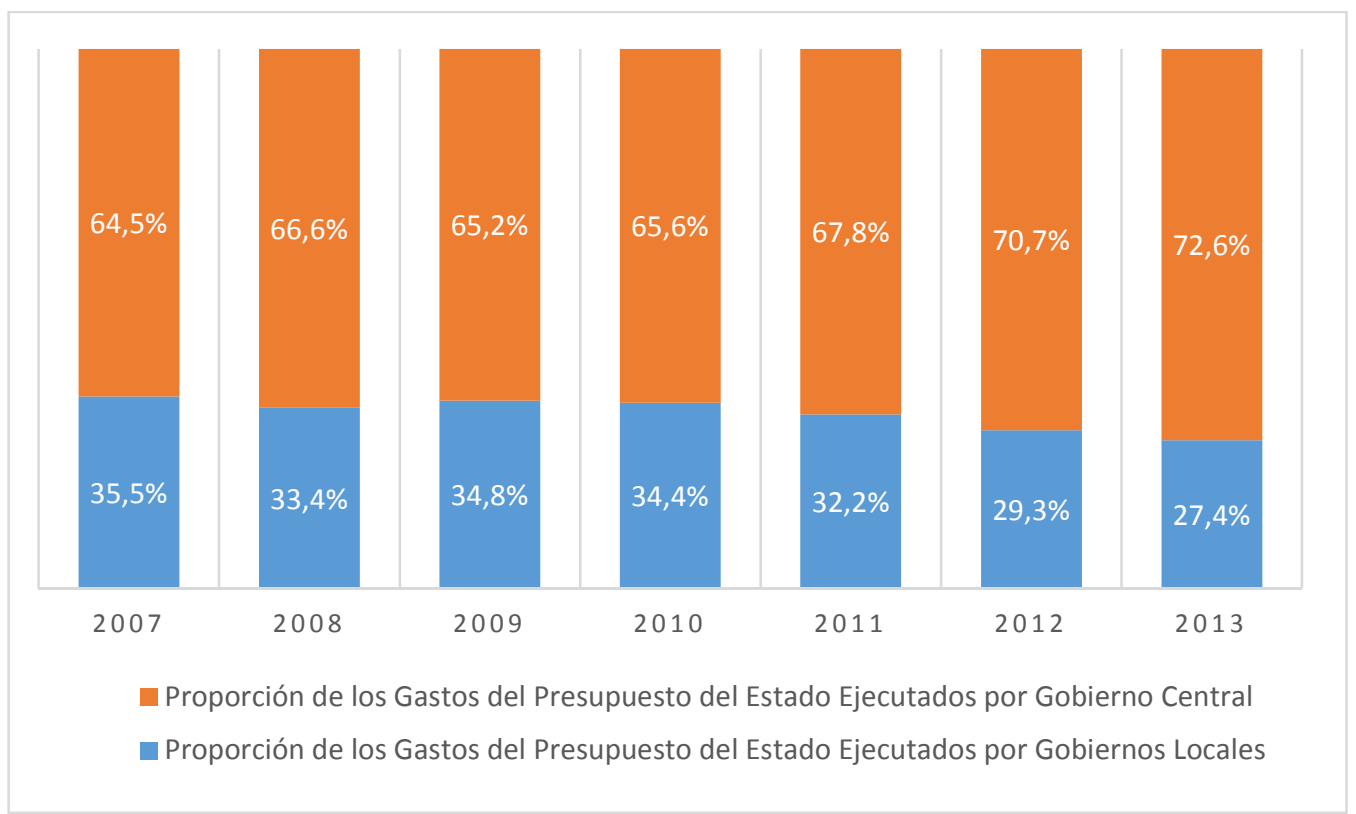

Gráfico 7 - Distribución de los Gastos del Presupuesto del Estado entre el Gobierno Central y los Gobiernos Locales 2007-2013

Fuente: Elaborado por las autoras a partir de datos de los Anuarios de la Oficina Nacional de Estadísticas e Información ONEI (www.onei.cu).

Por otra parte, al abrir las partidas que componen el Gasto del Presupuesto, algunas llaman la atención poderosamente. Puede apreciarse por ejemplo como los gastos de capital, que comprenden las inversiones, se ejecutan en su totalidad desde el presupuesto del Gobierno Central, lo que quiere decir que los Gobiernos Locales no tienen, o al menos no han tenido, la potestad de destinar una parte de su presupuesto a objetivos de inversión ${ }^{35}$. Lo anterior podría incluso adquirir una connotación mayor si se profundiza en lo que a los efectos del sistema de contabilidad nacional se nominaliza como inversión en Cuba, que puede incluir entre otros, la adquisición de una computadora.

Esta malformación puede contrastarse cuando en las Indicaciones Metodológicas para la elaboración del Plan 2015 se señala que "Los CAP y el CAM del Municipio Especial Isla de la Juventud emitirán criterios de la propuesta del plan de inversiones de las entidades nacionales, para lo cual los OACE y OSDE consultarán con los gobiernos locales los aspectos que le competen sobre las inversiones fundamentales que se propongan en sus respectivos territorios". No se prevee en ningún momento que sean los CAP los promotores de

\footnotetext{
${ }^{35}$ Ver el Gráfico 8.
} 
proyectos de inversión. Son receptores y por ello se les consulta, podría decirse que con la excepción de los proyectos que surjan por la vía de las Iniciativas Municipales para el Desarrollo Local (IMDL). ${ }^{36}$

Considérese también que Cuba con bajas tasas de inversión - en el entorno del $8 \%$ del PIB en los últimos cuatro años - ha visto concentradas estas en pocos territorios, algunos de los cuales se repiten con los mayores receptores de entidades, es el caso de las provincias de La Habana y Holguín ${ }^{37}$.

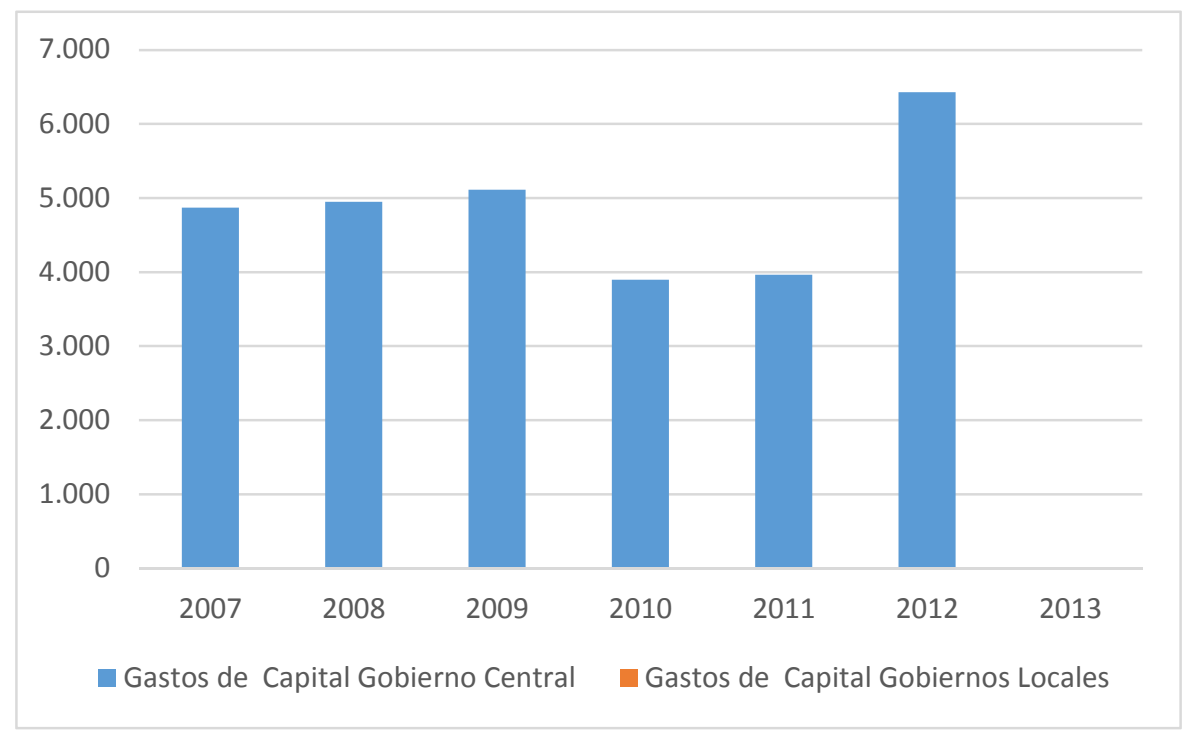

Gráfico 8 - Gastos de Capital del Gobierno Central y de los Gobiernos Locales 2007-2013 Fuente: Elaborado por las autoras a partir de datos de los Anuarios de la Oficina Nacional de Estadísticas e Información ONEI (www.onei.cu).

Para otras partidas seleccionadas, donde el gasto del presupuesto ejecutado por los Gobiernos Locales ha sido distinto de cero, puede apreciarse un punto de inflexión que interrumpió una senda de crecimiento e impuso una tendencia decreciente de la participación de los gobiernos locales en la ejecución de los gastos de estas partidas. Esta ha sido la regularidad en las esferas de Arte y Cultura a partir del año 2008, Ciencia y Tecnología con un brusco decrecimiento a un 1\% de participación a partir del año 2010,

\footnotetext{
${ }^{36}$ Indicaciones Metodológicas para la elaboración del Plan 2015. Capítulo XX. Planificación Territorial. Pág. 236.

${ }^{37}$ Datos de la Oficina Nacional de Estadísticas e Información ONEI (www.onei.cu).
} 
Deportes igualmente a partir del año 2010 y Bienestar y Asistencia Social a partir del año $2008 .^{38}$

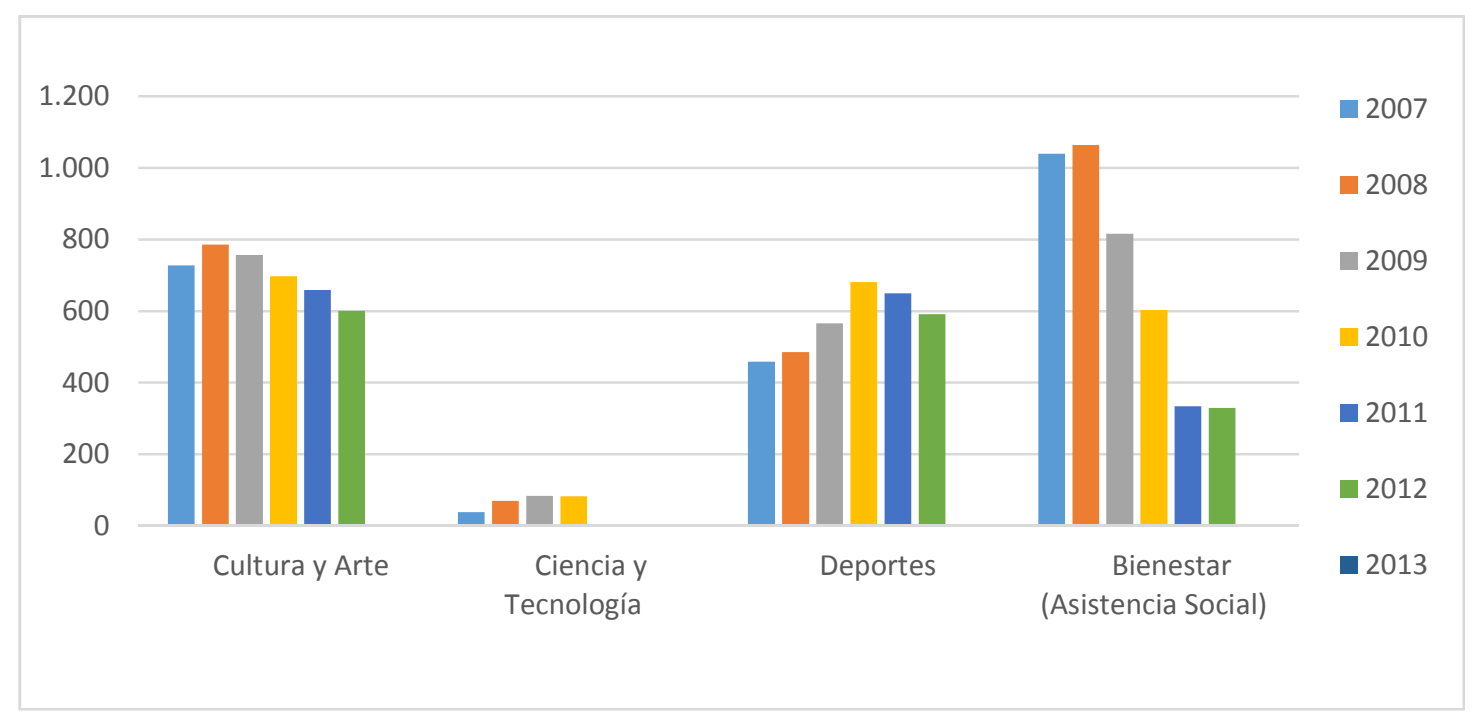

Gráfico 9 - Ejecución del Presupuesto de los Gobiernos Locales en partidas seleccionadas 2007$2013^{39}$

Fuente: Elaboración propia a partir de datos de los Anuarios de la Oficina Nacional de Estadísticas e Información ONEI (www.onei.cu).

Por tanto, la capacidad de reacción de los territorios, está dependiendo de sus ingresos más líquidos que son aquellos que se derivan de los proyectos provenientes de las IMDL que los municipios sean capaces de generar ${ }^{40}$. La rigidez en la ejecución de los gastos del presupuesto unido a este último elemento, puede dilatar la reacción de los territorios más rezagados. Es preciso que las autoridades nacionales asuman que las condiciones de partida son dispares y que en consecuencia las posibilidades para territorios atrasados de colocar

\footnotetext{
${ }^{38}$ Ver Gráfico 9.

${ }^{39}$ Nótese que en los Gráficos 8 y 9 no se contemplan valores para el año 2013. Lo anterior se debe a que en el Anuario Estadístico 2013 - Edición 2014 - existen datos que difieren con los publicados en años anteriores debido a cambios metodológicos que obedecen a nuevas agrupaciones de partidas y modificación en los momentos de registro de los ingresos en el presupuesto Central y en los Locales derivados del cronograma de implementación del Sistema de Contabilidad Gubernamental y esto hace imposible seguir la serie.

40 En el Capítulo XX de las Indicaciones Metodológicas para la elaboración del Plan 2015 se establece que "El aporte a los CAM, a partir de los ingresos o utilidades generados por los proyectos formarán parte del presupuesto en CUC del municipio (...), del cual se puede ejecutar el 70 por ciento en otros proyectos IMDL y el 30 por ciento restante en otros gastos necesarios para el territorio."
} 
proyectos competitivamente, y de encontrar fuentes de financiamiento externas que arriesguen su capital ex-ante en territorios con cierto grado de invisibilidad, son menores ${ }^{41}$.

Sobre la necesidad de contribuir a que este tipo de territorios menos favorecidos transiten hacia una senda de mayor prosperidad, Iñiguez (2013) señala: "Los lineamientos de la política económica y social del país que se ejecutan, deben tener entre sus prioridades la ingente necesidad ética de agudizar la mira sobre el mapa y priorizar la atención a espacios opacos del país, donde son menores las posibilidades de inserción en nuevos o reanimados procesos que se prevean o en marcha. El futuro inmediato enfrenta necesidades acumuladas y nuevas, portadoras de conflictos de pensar y actuar en el territorio".

\section{Consideraciones finales}

En la actualidad, uno de los principales retos que enfrenta el proceso de transformaciones del modelo de funcionamiento de la economía y la sociedad en Cuba dado su gran alcance, es responder integralmente a todas las necesidades de cambio, sin que los impactos de las medidas que se toman se contrapongan a la amplia gama de objetivos. En este trabajo se ha intentado reflejar justamente como algunos de los cambios introducidos no contribuyen directamente al progreso de los territorios cubanos, y cómo otros que se requieren en este mismo anhelo todavía no llegan. La prevalencia de un marco regulatorio en el que prima el verticalismo fundado en la escasez de recursos y los problemas de acceso a la divisa, hacen prevalecer la idea del territorio como soporte de las dinámicas sectoriales.

Este tiene que ser un proceso de crecimiento y aprendizaje constante, con la posibilidad de insertar modificaciones a las propias medidas y regulaciones en implantación. En este ámbito es evidente que la reorganización del sistema empresarial no puede perseguir la eficiencia sectorial, sin atender las disparidades territoriales existentes.

41 Un elemento novedoso de las Indicaciones Metodológicas para la elaboración del plan 2015, respecto a las del 2014, es que en la aprobación de estos proyectos, participará de manera directa solamente la entidad bancaria del territorio, como encargada de administrar estos fondos. Anteriormente se establecía la necesidad de contar con avales y criterios de los organismos nacionales implicados. 
De otro lado, las autoridades que conducen la actual política que rige la inversión extranjera en el país deberán enfocarse no solo en las oportunidades que surjan, sino también en el objetivo de influir en el avance equilibrado de los territorios. Si bien promover polos de desarrollo como fue en su momento el turismo con beneficios plausibles para territorios determinados como el entonces municipio de Varadero, y como puede ser ahora la Zona de Desarrollo Económico del Mariel, puede generar efectos multiplicadores, esto no debe obviar los riesgos que en términos de migraciones internas, abandono de producciones tradicionales, etc., podrían traer aparejadas políticas en esta dirección. Lo anterior especialmente, cuando el territorio no es un agente activo ni en la aprobación, ni en la promoción de inversiones en sus respectivas demarcaciones, sino que pende más bien de donde coloquen la mira los organismos sectoriales.

Igualmente, la idea de evitar generalizaciones con efectos no deseados y por tanto iniciar algunos cambios de manera experimental, tiene desventajas que deberán ser consideradas. La gradualidad en la extensión de la aplicación de la Contribución Territorial a la totalidad de los municipios del país por ejemplo, ha retrasado el impacto positivo que se espera de la recaudación siendo difícil encontrar los riesgos o peligros que podrían estar detrás de la decisión de ir paso a paso. En balance sobre la implementación de los Lineamientos de la política económica y social, y presentación del Plan de la Economía y el Presupuesto del Estado para el 2015, afortunadamente fue anunciada la extensión de la contribución territorial para el desarrollo local a todos los municipios del país, aunque se considera que esta estrategia tendrá un impacto más visible a partir del año 2016.

Asimismo, es impostergable la necesidad de aunar los esfuerzos en una sola dirección. La mayoría de las instituciones radicadas en el territorio, fundamentalmente las de subordinación local son hoy receptoras del ejercicio del poder desde múltiples vías y ha sucedido que de tantos que intentan observar por el mismo catalejo nadie consigue dilucidar el paisaje con claridad. Ha pasado esto con las entidades de subordinación local que muchas veces quedan abandonadas a lo que las administraciones locales pueden hacer, que sin posibilidades de emprender inversiones, es realmente poco. Hay que pensar que en definitiva la realización de los ciudadanos pasa, entre otros factores, por la satisfacción de las necesidades básicas en el entorno en que habitan. 
Hay brechas potenciales que podrían aprovecharse en mayor medida, y una de las más importantes tiene que ver con la necesidad de que los gobiernos locales se conviertan en promotores de la interacción entre la esfera pública y la floreciente iniciativa privada en los territorios. En cualquier caso, con independencia de los elementos que necesariamente tendrán que transformarse dentro del marco regulatorio y que escapan en este momento a la gestión local, es necesario que los territorios avancen en la identificación de las barreras y en las formas de sortearlas o derribarlas.

\section{Referencias}

Asamblea Provincial del Poder Popular de Ciudad de La Habana. Ley No. 91 de los Consejos Populares aprobado por la Asamblea Nacional el 13 de julio del 2000. Documentos Normativos de la labor de los órganos del Poder Popular y las entidades de su subordinación. La Habana, 485 Aniversario.

Consejo de Ministros (2012), Decreto 301 del Consejo de Ministros sobre las Funciones Estatales y de Gobierno en Artemisa y Mayabeque, aprobado el 12 de octubre de 2012.

Decreto - Ley No. 320 del Consejo de Estado, Decreto No. 323 del Consejo de Ministros, Resoluciones No. 181/2014 y 203/2014 del Ministerio de Finanzas y Precios y Resolución No. 17/2014 del Ministerio de Trabajo y Seguridad Social, documentos publicados en la Gaceta Oficial de la República de Cuba No. 21 Extraordinaria de 28 de abril de 2014.

ÍÑIGUEZ, L. (2013), “Espacios luminosos y opacos ¿Para quienes?”, Revista Digital GUCID- Órgano del Programa Ramal del MES "Gestión universitaria del conocimiento y la innovación para el desarrollo". Año III. No. 31, marzo-2013. La Habana, Cuba.

ÍÑIGUEZ, L. (2014), “¿De quiénes son los territorios?”, Revista Miradas a la Economía Cubana. Desde una perspectiva territorial. Compiladores Omar Everleny Pérez Villanueva y Ricardo Torres Pérez. Editorial Caminos, La Habana, 2014.

Ley No. 110/10 de la Asamblea Nacional del Poder Popular (ANPP) modificativa de la Ley No. 1304 del 3 de julio de 1976, de la División Político Administrativa, publicada en la Gaceta Oficial de la República de Cuba No. 023 Extraordinaria del 2 de septiembre de 2010,

Ley No. 113 del Sistema Tributario, publicada en la Gaceta Oficial de la República de Cuba No.053 Ordinaria del 21 de Noviembre de 2012.

Ley No. 117 del Presupuesto del Estado para el año 2014, publicada en Gaceta Oficial de la República de Cuba No. 5 Extraordinaria de 20 de enero de 2014.

Ley No. 118 de la Inversión Extranjera, aprobada por la Asamblea Nacional del Poder Popular el 29 de marzo de 2014. Tabloide Especial de Granma. Abril de 2014.

Ley No. 119 del Presupuesto del Estado para el año 2015, publicada en la Gaceta Oficial No. 1 Extraordinaria de 9 de enero de 2015

Ministerio de Economía y Planificación (MEP). Indicaciones Metodológicas para la elaboración del Plan 2014. La Habana, Cuba. 
Ministerio de Economía y Planificación (MEP). Indicaciones Metodológicas para la elaboración del Plan 2015. La Habana, Cuba.

Ministerio de Finanzas y Precios (2014), Resolución 170 del Ministerio de Finanzas y Precios, publicada el 31 de marzo de 2014.

Partido Comunista de Cuba (PCC), "Lineamientos de la Política Económica y Social del Partido y la Revolución". VI Congreso PCC. La Habana, Cuba 2011.

RAMOS, P. \& LOIS, R. (2013): “Planificación y Ordenación Territorial en Cuba desde 1959: Barreras institucionales actuales y perspectivas". Revista Ciudad y Territorio: Estudios Territoriales, Vol. XLV, № 177, otoño 2013.

TRIANA, J. (2014), "Entrampados en el fuego amigo", Revista Miradas a la Economía Cubana. Desde una perspectiva territorial. Compiladores Omar Everleny Pérez Villanueva y Ricardo Torres Pérez. Editorial Caminos, La Habana, 2014.

\section{Sitios Web}

GRANMA (2014), "Extienden la experiencia en Artemisa y Mayabeque hasta el 2016", publicado por la Redacción Nacional del periódico Granma el 6 de julio de 2014 en http://www.granma.cu/cuba/2014-0706/extienden-la-experiencia-en-artemisa-y-mayabeque-hasta-el-2016

CUBA INFORMACION (2014), "Logros en el nuevo modelo experimental de Gobierno de la provincia de Artemisa", entrevista concedida por Raúl Rodríguez, jefe del Consejo de la Administración Provincial a la periodista del periódico Juventud Rebelde Adianez Fernández Izquierdo. Publicada el jueves 12 de Junio de 2014 en http://www.cubainformacion.tv/index.php/politica/56967-logros-en-el-nuevo-modelo-experimentalde-gobierno-de-la-provincia-de-artemisa

INFORMES DE ORGANIZACIÓN INSTITUCIONAL. PRINCIPALES ENTIDADES (2009-2014) publicados por la Oficina Nacional de Estadísticas e Información ONEI (www.onei.cu).

MARTín, R. et al, (2012), "Experiencias en Artemisa y Mayabaque", publicado por el periódico Juventud Rebelde el 1ro de agosto de 2011 en http://www.juventudrebelde.cu/cuba/2012-12-11/experiencias-enartemisa-y-mayabaque/

MARTíNEZ , L. (2014): “Economía cubana avizora mayores crecimientos en el 2015". Periódico Granma. 30 de noviembre de 2014 21:11:13. http://www.granma.cu/cuba/2014-11-30/economia-cubana-avizora-mayorescrecimientos-en-el-2015

RODRÍGUEZ, J.A.; Barrios, M. \& RODRÍGUEZ GAVILÁN, A. (2011), "Artemisa y Mayabeque experimentarán nuevas formas de dirección", publicado por el períodico Juventud Rebelde el 1ro de agosto de 2011 en http://www.juventudrebelde.cu/cuba/2011-08-01/aplicaran-con-caracter-experimental-separacion-de-ladireccion-de-los-consejos-de-administracion-y-de-las-asambleas-provinciales-y-municipales-en-los-nuevosterritorios-de-artemisa-y-mayabeque/ 